\title{
Plasma TF activity predicts cardiovascular mortality in patients with acute myocardial infarction
}

\author{
Birgit A Steppich ${ }^{1,2}$, Siegmund Lorenz Braun ${ }^{3}$, Andreas Stein ${ }^{1,2}$, \\ Gabriele Demetz ${ }^{1,2}$, Philip Groha1,2, Albert Schömig1,2, Nicolas von \\ Beckerath1,2, Adnan Kastrati1,2 and Ilka Ott*1,2
}

\begin{abstract}
Address: ${ }^{1}$ Medizinische Klinik, Klinikum rechts der Isar der Technischen Universität München, , Munich, Germany, ${ }^{2}$ Klinik für Kardiologie, Deutsches Herzzentrum München der Technischen Universität, Munich, Germany and ${ }^{3}$ Institut für Laboratoriumsmedizin, Deutsches Herzzentrum München der Technischen Universität, Munich, Germany

Email: Birgit A Steppich - steppich@dhm.mhn.de; Siegmund Lorenz Braun - braun@dhm.mhn.de; Andreas Stein - stein@dhm.mhn.de; Gabriele Demetz - demetz@dhm.mhn.de; Philip Groha - groha@dhm.mhn.de; Albert Schömig - schomig@dhm.mhn.de; Nicolas von Beckerath - nbeckerath@dhm.mhn.de; Adnan Kastrati - akastrati@dhm.mhn.de; Ilka Ott* - ott@dhm.mhn.de

* Corresponding author
\end{abstract}

Published: 2 July 2009

Thrombosis Journal 2009, 7:II doi:10.1 186/1477-9560-7-II
Received: 25 February 2009

Accepted: 2 July 2009

This article is available from: http://www.thrombosisjournal.com/content/7/I/II

(C) 2009 Steppich et al; licensee BioMed Central Ltd.

This is an Open Access article distributed under the terms of the Creative Commons Attribution License (http://creativecommons.org/licenses/by/2.0), which permits unrestricted use, distribution, and reproduction in any medium, provided the original work is properly cited.

\begin{abstract}
Objectives and Background: Tissue factor (TF) contributes to thrombosis following plaque disruption in acute coronary syndromes (ACS). Aim of the study was to investigate the impact of plasma TF activity on prognosis in patients with ACS.

Methods and Results: One-hundred seventy-four patients with unstable Angina pectoris (UAP) and I I 2 patients with acute myocardial infarction (AMI) were included with a mean follow up time of 3.26 years. On admission, plasma TF activity was assessed. Patients were categorized into 2 groups: a high-TF activity group with TF $>24 \mathrm{pmol} / \mathrm{L}$ and low TF activity group with $\mathrm{TF} \leq 24 \mathrm{pmol} /$ L. Fifteen cardiovascular deaths occurred in the UAP group and 16 in the AMI group. In AMI TF activity was $24,9 \pm 2,78 \mathrm{pmol} / \mathrm{l}$ (mean $\pm \mathrm{SEM}$ ) in survivors and 40,9 $\pm 7,96 \mathrm{pmol} / \mathrm{l}$ in nonsurvivors $(P=0.024)$. In uAP no differences were observed $(25.0 \pm 8.04 \mathrm{pmol} / \mathrm{L}$ nonsurvivors vs. $25.7 \pm 2.14$ $\mathrm{Pmol} / \mathrm{L}$ survivors; $\mathrm{P}=0.586)$. Kaplan-Meier estimates of survival at 3.26 years regarding TF activity in AMI were $81.3 \%$ and $92.2 \%$ with an hazard ratio of 3.02 (95\% Cl [I.05-8.79], $\mathrm{P}=0.03)$. The Cox proportional hazards model adjusting for correlates of age and risk factors showed that plasma TF activity was an independent correlate of survival (hazard ratio 9.27, 95\% $\mathrm{Cl}$ [1.24-69.12], $\mathrm{P}=0.03$ ). In an additional group of patients with UAP and AMI, we identified circulating microparticles as the prevailing reservoir of plasma TF activity in acute coronary syndromes.
\end{abstract}

Conclusion: Systemic TF activity in AMI has an unfavorable prognostic value and as a marker for dysregulated coagulation may add to predict the atherothrombotic risk.

\section{Introduction}

Atherothrombosis, characterized by a disruption of atherosclerotic lesions superimposed with thrombus formation, is the major cause of acute coronary syndromes
(ACS) and cardiovascular death. Tissue factor (TF) as the cellular initiator of the extrinsic coagulation cascade plays a key role in intravascular thrombus formation by allosterically activating factor VII (FVII). Over the last decades 
it has been shown that, in addition to intravascular TF, circulating TF is implicated in arterial and venous thrombosis [1-5]. Current studies have shown that plasma TF is comprised of: a) TF associated with microparticles (MP) and b) an alternatively spliced TF variant that lacks the transmembrane domain [6]. In living mice this plasma or blood-borne TF accumulates in newly formed thrombi via monocyte-derived MP and contributes to thrombus growth and propagation $[2,7]$. Several studies have demonstrated increased levels of circulating TF in patients with unstable Angina pectoris (uAP) and acute myocardial infarction (AMI) [8-12]. Therefore, it has long been speculated that, in cases with no plaque rupture or only fractional superficial erosion, thrombus formation may depend on circulating levels of TF. Consistent with this idea, several studies suggest that the levels of circulating TF and other haemostatic biomarkers may correlate to adverse cardiovascular events and mortality in patients with ACS [13-17]. However, all these data are based on immunoreactive measurements and provide no evidence that circulating TF in ACS is functional or is capable of contributing to systemic hypercoagulability. To date, data addressing plasma TF activity are lacking. Since TF antigen measurements do not necessarily reflect the functional capacity and integrity of TF, measuring TF activity might be a better approach for stratifying cardiovascular risk. Therefore, aim of the present study was to investigate plasma TF activity in patients with ACS and evaluate its capacity to predict future cardiovascular and overall mortality.

\section{Methods \\ Study population}

This prospective study enrolled 286 consecutive patients that were referred to the hospital between July 2001 and February 2002 for acute coronary syndromes. The diagnosis of AMI was established by the presence of chest pain lasting $>20$ minutes associated with electrocardiographic and enzymatic changes (Peak $\mathrm{CK} \geq 300 \mathrm{U} / \mathrm{l}$ ). Electrocardiographic changes included: an ST-segment elevation of at least $0.1 \mathrm{mV}$ in two or more limb leads, an elevation of at least $2 \mathrm{mV}$ in two or more contiguous precordial leads on the surface electrocardiogram, or a new-onset left bundle branch block. Unstable Angina was defined as a crescendo pattern of chest pain at rest with documented non-specific electrocardiographic changes including: a transient ST segment depression or elevation of at least $0.1 \mathrm{mV}$ in at least 2 contiguous electrocardiographic leads or a $\mathrm{T}$ wave inversion. Patients with interfering non-cardiac diseases and malignancies were not included in the study. On admission, blood was drawn from all subjects under standardized conditions and plasma samples were stored at $-80^{\circ} \mathrm{C}$ until analysis. All patients underwent urgent coronary angiography for percutaneous coronary intervention (PCI). The study protocol was approved by the institu- tional ethics committee and informed consent was obtained from all subjects.

To analyze the sources of circulating TF activity, an additional group of 36 consecutive patients with uAP and AMI were recruited between December 2005 and November 2006. A control group comprised 28 patients with stable angina (sAP) undergoing elective PCI.

\section{Biochemical and microparticle analysis}

Plasma TF activity was measured with an FXa generation assay (Actichrome TF, American Diagnostica; Detection treshold $2 \mathrm{pM}$, intra-assay variabilities $<10 \%$; inter-assay variabilities $<10 \%$ ). To inhibit endogenous TFPI TF activity was measured using an FXa generation assay in the absence and presence of $100 \mu \mathrm{g} / \mathrm{ml}$ rabbit anti-TFPI-1 IgG (kindly provided by Dr. W. Ruf) or nonimmune rabbit IgG (Sigma). TF activity in the presence of anti-TFPI mAbs represents the total TF activity in the plasma. TF activity associated with circulating MP was measured by first isolating MP by antibody capture and then analyzing FXa generation using a commercial available assay (Actichrome ${ }^{\circledR}$ Microparticle activity \#817, American diagnostic; Detection treshold $\leq 0,05 \mathrm{nM}$, intra-assay variabilities 3$8 \%$; inter-assay variabilities 5-10\%). Plasma TF antigen was measured by immunoassay (Imubind Tissue Factor ELISA kit, American Diagnostica; Detection treshold 1,4 $\mathrm{pM}$, intra-assay variabilities $4,5 \%$; inter-assay variabilities $7,5 \%)$.

Serum concentrations of creatine kinase, C-reactive protein (CRP), fibrinogen, and brain natriuretic protein (BNP) (Roche NT-pro-BNP sandwich electrochemiluminescent assay, Roche Diagnostics, Mannheim, Germany) were determined in routine clinical chemistry laboratory analyses.

For analysis of circulating MP, platelet free plasma (PFP) was immediately snap frozen in liquid nitrogen and stored at $-80^{\circ} \mathrm{C}$ until use. To separate MP from PFP, aliquots of $250 \mu \mathrm{l}$ were centrifuged for $60 \mathrm{~min}$ at $100,000 \times \mathrm{g}$; then $225 \mu$ of the supernatant was decanted and stored for further analysis. MP were resuspended in the remaining $25 \mu$ l. Flowcytometric analyses of MP suspensions were performed according to the manufacturer's instructions using annexin V Alexa Fluor ${ }^{\otimes} 568$ in an appropriate buffer (Boehringer Mannheim, Germany) and either specific monoclonal antibodies $(\mathrm{mAb})$ or isotype-matched control antibodies. Antibodies were labeled with fluoresceinisothiocyonate (FITC), peridinin-chlorophyll-protein complex (PerCP), or Allophycocyanin (APC) and included: FITC-conjugated anti-TF antibody (American diagnostic), CD41 PerCP (Coulter), and CD 66 APC (BectonDickinson). Before FACS analysis was performed, a defined number of latex beads (LB30, Sigma) were added 
to the samples in order to calculate the absolute amount of MPs. Analysis was stopped when 5000 beads were counted.

\section{Clinical follow-up and endpoint definition}

All enrolled patients were contacted for follow-up with a mean of 3.26 years after the percutaneous coronary intervention. The primary outcome measures of the study were: cardiovascular mortality, which included a) fatal myocardial infarction and b) ventricular arrhythmias with heart failure as a consequence of MI, and all cause mortality.

\section{Statistical analysis}

Discrete variables were expressed as counts (\%) and compared by chi-square or Fisher's exact test. Continuous variables were expressed as mean \pm S.D. and compared by the Wilcoxon's rank sum test. The Youden-index was used to determine statistically reliable cut-off value of TF by maximizing the sum of sensitivity and specificity in reference to observed survival state. In this term, area under the ROC-curve (AUC) was reported to assess overall prognostic performance of plasma TF activity. Further, the corresponding 95\% confidence interval of AUC was reported indicating statistically significant predictive capability if the critical value of 0.5 is not included. Spearman-Rho correlation coefficient was used to identify correlates of TF activity. Survival analysis was performed by applying the Kaplan-Meier method. Differences in survival were assessed with log rank test. Cox's proportional hazard model was used to assess the independent association of TF activity with mortality. All statistical analyses were performed using SPSS 15.0. P-values < 0.05 were considered statistically significant.

\section{Results}

\section{Baseline characteristics}

Of the 286 patients enrolled in the study, 112 presented with AMI and 174 were classified as uAP. During the follow up 16 cardiovascular deaths and 8 non-cardiovascular deaths were reported among patients with AMI; similarly, 15 cardiovascular deaths and 9 non-cardiovascular deaths were reported among patients with $\mathrm{uAP}$. In AMI the majority of cardiovascular death occurred in the first year caused by cardiogenic shock or terminal heart failure, whereas in uAP only 3 deaths occurred during this time. The majority of cardiovascular death in uAP occurred after 1 year or later due to reinfarction, terminal heart failure and sudden cardiac death. According to a receiver operating characteristic (ROC) analysis patients were categorized into 2 groups: the high-TF activity group included patients with TF values $>24 \mathrm{pmol} / \mathrm{L}$, the low TF activity group included patients with TF values $\leq 24 \mathrm{pmol} / \mathrm{L}$. ROC - analysis revealed a substantial prognostic capability of TF with an AUC of 0.66 (95\%CI: 0.51 to 0.81$)$. The clini- cal characteristics of each patient group and the incidence of cardiovascular death are shown in Table 1 and 2. As expected, patients with AMI that died from cardiovascular causes were older and had higher peak CK and NTproBNP levels at baseline than those that survived (data not shown). Also, on admission they had a reduced left ventricular ejection fraction and presented with a higher Killip class. Patients with uAP that died had a higher prevalence of hypertension and preclinical resuscitation than those that survived. No other characteristics were different between patients that died and those that survived. The majority of AMI patients received abciximab, and the majority of uAP patients received only heparin.

\section{TF activity and cardiovascular mortality}

In patients with AMI the TF activity was $24.9+2.78 \mathrm{pmol} /$ $\mathrm{L}($ mean+SEM) in survivors and $40.9+7.96 \mathrm{pmol} / \mathrm{L}$ in nonsurvivors $(P=0.024)$. Kaplan-Meier estimates of survival regarding TF activity in AMI above or below $24 \mathrm{pmol}$ were $81.3 \%$ and $92.2 \%$ with an odds ratio of 3.02 (95\% CI [1.05-8.79], $\mathrm{P}=0.03$; Figure 1$)$. In uAP no differences in TF activity were observed in survivors and nonsurvivors $(25.7 \pm 2.14 \mathrm{pmol} / \mathrm{L}$ versus $25.0 \pm 8.04 \mathrm{pmol} / \mathrm{L} ; \mathrm{P}=0.59)$. The Cox proportional hazards model adjusting for correlates of mortality showed that plasma TF activity was a prognostic factor of mortality in patients with AMI (Table 3).

\section{Relationships between TF activity, inflammation, and necrosis}

Among patients with AMI, TF activity correlated with parameters of myocardial necrosis (peak CK: $\mathrm{R}=0.22, P=$ 0.025; peak CK-MB: $\mathrm{R}=0.23 ; P=0.019$; CK on admission: $\mathrm{R}=0.23, P=0.037)$, Killip class $(\mathrm{R}=0.22, P=0.022)$, and incidence of cardiopulmonary resuscitation on admission ( $\mathrm{R}=0.20, P=0.037)$. No association was found between TF activity and markers of inflammation. In contrast, among patients with UAP, TF activity was only correlated with parameters of inflammation (CRP: $\mathrm{R}=0.17, P=$ 0.03; fibrinogen: $\mathrm{R}=0.23, P=0.005$, and NT-proBNP: $\mathrm{R}$ $=0.16, P=0.035)$ but not with parameters of myocardial necrosis, Killip class, or incidence of cardiopulmonary resuscitation.

\section{Sources of Circulating TF}

To evaluate the functional significance and the underlying sources of circulating $\mathrm{TF}$, we performed a second study comparing 36 patients with UAP and AMI and 28 control patients with sAP. In contrast to patients with ongoing ACS, almost no TF activity was detected in the circulation of sAP patients $(0.0 \pm 0.0 \mathrm{pmol}$ vs $0.5 \pm 0.16 \mathrm{pmol}, P=$ 0.008 , Table 4 ), even after abrogating the endogenous inhibition by TFPI- $1(0.98 \pm 0.4$ pmol vs $12.63 \pm 1.82$ pmol, $P<0.001)$. 
Table I: Baseline characteristics of patients with acute myocardial infarction $(n=|| 2)$

\begin{tabular}{|c|c|c|c|}
\hline Characteristic & TF activity $\leq 24 \mathrm{pmol}(\mathrm{n}=64)$ & TF activity $>24 \mathrm{pmol}(\mathrm{n}=48)$ & $P$ \\
\hline TF Activity, (pmol) & $7.0 \pm 0.90$ & $54.2 \pm 3.30$ & $<0.001$ \\
\hline TF Activity + anti TFPI, (pmol) & $39.7 \pm 2.25$ & $65.8 \pm 2.99$ & $<0.001$ \\
\hline \multicolumn{4}{|l|}{ Demographics } \\
\hline Median age, years & $64.5 \pm 1.54$ & $58.7 \pm 1.95$ & 0.02 \\
\hline Male sex & $54(84.4 \%)$ & 37 (77.1\%) & 1.0 \\
\hline Number of CV death (n) & $5(7.8 \%)$ & II (22.9\%) & 0.02 \\
\hline Time to death (days) & $437.3 \pm 145.72$ & $218.0 \pm 55.63$ & 0.68 \\
\hline Days of follow up (days) & $1460.0 \pm 0.0$ & $1460.0 \pm 0.0$ & 1.0 \\
\hline \multicolumn{4}{|l|}{ Pevious medical history } \\
\hline Myocardial infarction & 15 (24.4\%) & $8(16.7 \%)$ & 0.005 \\
\hline$A C V B$ & $5(7.8 \%)$ & $2(4.2 \%)$ & 0.001 \\
\hline \multicolumn{4}{|l|}{ Cardiovascular risk factors } \\
\hline Arterial hypertension & $40(62.5 \%)$ & 34 (70.8\%) & 0.17 \\
\hline Diabetes mellitus & $14(21.9 \%)$ & $15(31.3 \%)$ & 0.001 \\
\hline Hypercholesterolemia & 39 (60.9\%) & $25(52.1 \%)$ & 0.41 \\
\hline Current smoker & $42(65.6 \%)$ & $36(75.0 \%)$ & 0.001 \\
\hline \multicolumn{4}{|l|}{ Biochemical markers } \\
\hline Peak creatine kinase, U/I & $|475.0 \pm 357.9|$ & $1897.7 \pm 276.5$ & 0.03 \\
\hline C-reactive protein, $\mathrm{mg} / \mathrm{dl}$ & $44.7 \pm 11.22$ & $26.2 \pm 6.79$ & 0.25 \\
\hline NT-pro-BNP, pg/ml & $1739.4 \pm 402.93$ & $3946.8 \pm 1442.53$ & 0.28 \\
\hline \multicolumn{4}{|l|}{ Clinical data } \\
\hline Prehospital CPR & $5(7.8 \%)$ & $10(20.8 \%)$ & 0.05 \\
\hline Cardiogenic shock & $9(14.1 \%)$ & $13(27.1 \%)$ & 0.09 \\
\hline \multicolumn{4}{|l|}{ Killip's class } \\
\hline 1 & 47 (73.4\%) & $25(52.1 \%)$ & 0.04 \\
\hline II & $8(12.5 \%)$ & $10(20.8 \%)$ & 0.09 \\
\hline III & $3(4.7 \%)$ & $6(12.5 \%)$ & 0.60 \\
\hline IV & $6(9.4 \%)$ & $7(14.6 \%)$ & 0.40 \\
\hline \multicolumn{4}{|l|}{ Angiographic data } \\
\hline Left ventricular function & $46.2 \pm 1.56$ & $45.3 \pm 1.97$ & 0.77 \\
\hline \multicolumn{4}{|l|}{ Target vessel } \\
\hline LAD & 27 (42.2\%) & 29 (60.4\%) & 0.30 \\
\hline RCA & 30 (46.9\%) & $12(25.0 \%)$ & 0.03 \\
\hline LCx & 7 (10.9\%) & $7(14.6 \%)$ & 0.57 \\
\hline \multicolumn{4}{|l|}{ Extent of coronary artery } \\
\hline \multicolumn{4}{|l|}{ Disease } \\
\hline I-vessel-disease & 18 (28.1\%) & 15 (31.3\%) & 0.72 \\
\hline 2-vessel-disease & 18 (28.1\%) & $14(29.2 \%)$ & 0.29 \\
\hline 3-vessel-disease & $28(43.8 \%)$ & $19(39.6 \%)$ & 0.16 \\
\hline \multicolumn{4}{|l|}{ Medication on admission } \\
\hline Aspirin & $64(100 \%)$ & 48 (100\%) & 1.0 \\
\hline Heparin & $12(18.8 \%)$ & $4(8.3 \%)$ & 0.07 \\
\hline Clopidogrel & $54(84.4 \%)$ & 44 (91.7\%) & 0.83 \\
\hline Beta-Blockers & $18(28.1 \%)$ & $10(20.8 \%)$ & 0.07 \\
\hline ACE-Inhibitors & $10(15.6 \%)$ & $7(14.6 \%)$ & 0.86 \\
\hline Statins & $12(18.8 \%)$ & $5(10.4 \%)$ & 0.85 \\
\hline
\end{tabular}

ACVB: aortocoronary bypass grafting; CPR: cardiopulmonary resuscitation

Currently there are two known sources that contribute to circulating TF: alternatively spliced soluble TF (asTF) and $\mathrm{MP}$ bearing membrane-bound TF. In order to analyze both fractions we applied a differential centrifugation procedure, resulting in pellet and supernatant fractions. FACS analysis showed the pellet was enriched in MP, while no viable cell particles were found in the supernatant (Figure 2A, B, F, G). Nevertheless, both fractions contained comparable amounts of TF antigen (Figure $2 \mathrm{C}, \mathrm{H}$ ). We rea- soned that the pellet fraction most likely represented circulating MPs bearing TF, and the supernatant fraction contained a soluble form of TF. The pellet fraction exhibited a clear TF activity, which further increased after inhibition of endogenous TFPI. However, the supernatant had only little TF activity, devoid of any regulation by TFPI (Figure 2D, I). No TF activity was detected in the supernatant using the assay for MP-bound TF activity (Figure 2E, $\mathrm{J})$. In the pellet, TF activity measured by the chromogenic 
Table 2: Baseline characteristics of patients with unstable Angina pectoris $(n=174)$

\begin{tabular}{|c|c|c|c|}
\hline Characteristic & TF activity $\leq 24 \mathrm{pmol}(\mathrm{n}=106)$ & TF activity $>24$ pmol $(\mathrm{n}=68)$ & $\mathrm{P}$ \\
\hline TF Activity, (pmol) & $7.39 \pm 0.60$ & $53.9 \pm 2.76$ & $<0.001$ \\
\hline TF Activity + anti TFPI, (pmol) & $41.36 \pm 1.92$ & $66.17 \pm 2.38$ & $<0.001$ \\
\hline \multicolumn{4}{|l|}{ Demographics } \\
\hline Median age, years & $66.6 \pm 1.05$ & $67.2 \pm 1.36$ & 0.79 \\
\hline Male sex & 76 (71.7\%) & 37 (54.4\%) & 0.88 \\
\hline Number of CV death (n) & $10(9.4 \%)$ & $5(7.4 \%)$ & \\
\hline Time to death (days) & $655.47 \pm 123.49$ & $642.78 \pm 137.90$ & 0.93 \\
\hline Days of follow up (days) & $14 \mid 4.48 \pm 11.24$ & $1443.75 \pm 8.39$ & 0.13 \\
\hline \multicolumn{4}{|l|}{ Previous medical history } \\
\hline Myocardial infarction & 35 (33.0\%) & 21 (30.9\%) & 0.74 \\
\hline$A C V B$ & $13(12.3 \%)$ & $7(10.3 \%)$ & 0.69 \\
\hline \multicolumn{4}{|l|}{ Cardiovascular risk factors } \\
\hline Arterial hypertension & 91 (85.9\%) & $56(82.4 \%)$ & 0.54 \\
\hline Diabetes mellitus & $28(26.4 \%)$ & $28(41.2 \%)$ & 0.07 \\
\hline Hypercholesterolemia & $69(65.1 \%)$ & $40(58.8 \%)$ & 0.35 \\
\hline Current smoker & 51 (48.1\%) & $30(44.1 \%)$ & 0.50 \\
\hline \multicolumn{4}{|l|}{ Biochemical markers } \\
\hline Peak creatine kinase, U/l & $92.7 \pm 5.39$ & $188.2 \pm 15.39$ & 0.56 \\
\hline C-reactive protein, $\mathrm{mg} / \mathrm{dl}$ & $22.9 \pm 4.00$ & $24.8 \pm 4.37$ & 0.19 \\
\hline NT-pro-BNP, pg/ml & $2321.24 \pm 490.50$ & $2176.1 \pm 306.79$ & 0.13 \\
\hline \multicolumn{4}{|l|}{ Clinical data } \\
\hline Prehospital CPR & I (0.9\%) & I (I.5\%) & 0.75 \\
\hline Cardiogenic shock & $2(1.9 \%)$ & $0(0.0 \%)$ & 0.26 \\
\hline \multicolumn{4}{|l|}{ Killip's class } \\
\hline 1 & $103(97.2 \%)$ & $64(94.1 \%)$ & 0.32 \\
\hline II & $2(1.9 \%)$ & $\mathrm{I}(\mathrm{I} .5 \%)$ & 0.84 \\
\hline III & $0(0.0 \%)$ & $2(2.9 \%)$ & 0.08 \\
\hline IV & $\mathrm{I}(0.9 \%)$ & I (I.5.\%) & 0.75 \\
\hline \multicolumn{4}{|l|}{ Angiographic data } \\
\hline Left ventricular function & $52.6 \pm 1.38$ & $51.5 \pm 1.77$ & 0.67 \\
\hline \multicolumn{4}{|l|}{ Target vessel } \\
\hline LAD & 44 (4I.5\%) & $33(48.5 \%)$ & 0.27 \\
\hline RCA & $33(31.1 \%)$ & $24(35.3 \%)$ & 0.20 \\
\hline LCx & $29(27.4 \%)$ & II (16.8\%) & 0.14 \\
\hline \multicolumn{4}{|l|}{ Extent of coronary artery } \\
\hline \multicolumn{4}{|l|}{ Disease } \\
\hline I-vessel-disease & 21 (19.8\%) & $13(19.1 \%)$ & 0.90 \\
\hline 2-vessel-disease & $32(30.2 \%)$ & $21(30.9 \%)$ & 0.76 \\
\hline 3-vessel-disease & $53(50.0 \%)$ & $34(50.0 \%)$ & 0.85 \\
\hline \multicolumn{4}{|l|}{ Medication on admission } \\
\hline Aspirin & $106(100 \%)$ & $68(100.0 \%)$ & 1.00 \\
\hline Heparin & $63(63.4 \%)$ & $38(55.9 \%)$ & 0.79 \\
\hline Clopidogrel & 91 (85.8\%) & $49(72.1 \%)$ & 0.54 \\
\hline Beta-Blockers & $62(58.5 \%)$ & $38(55.8 \%)$ & 0.82 \\
\hline ACE-Inhibitors & $53(50.0 \%)$ & $29(42.7 \%)$ & 0.34 \\
\hline Statins & 44 (4I.5\%) & $24(35.3 \%)$ & 0.46 \\
\hline
\end{tabular}

ACVB: aorto-coronary bypass crafting; CPR: cardiopulmonary resuscitaion

and the MP assays were comparable, indicating that MPs were a main component of plasma TF activity. In contrast, in the supernatant, soluble forms of TF contributed to circulating TF antigen, but possessed no TF activity and were not regulated by TFPI. Flow cytometric characterization of the MPs of patients with ACS revealed that circulating MPs stained double-positive for platelet (CD41) and granulocyte (CD66b) markers (Table 5). Among the MPs that were Annexin+TF+, the percentages that were also
CD41+CD66b+ correlated with the basal TF activity. Thus, in the plasma of patients with ACS, the TF activity was a consequence of circulating MPs.

\section{Discussion}

This study shows that, the baseline plasma TF activity was an independent predictor for cardiovascular death in patients with AMI; furthermore, plasma TF activity was correlated to parameters of myocardial necrosis. In con- 
Table 3: Cox regression analysis for cardiovascular mortality in AMI patients in relation to risk factors

\begin{tabular}{lllll}
\hline & Significance & $\operatorname{Exp}(\mathrm{B})$ & $95 \% \mathrm{Cl}$ lower & $95 \% \mathrm{Cl}$ upper \\
\hline TF activity & 0.03 & 9.27 & 1.24 & 69.12 \\
Age & 0.01 & 1.07 & 1.01 & 1.13 \\
Hypertension & 0.72 & 0.60 & 0.04 & 9.83 \\
Diabetes & 0.96 & 1.06 & 0.19 & 5.84 \\
Smoking & 0.96 & 0.97 & 0.31 & 3.03 \\
Cholesterol & 0.79 & 1.46 & 0.09 & 24.44 \\
\hline
\end{tabular}

trast, in patients with uAP, circulating TF activity was not related to the long term prognosis.

This is the first study to address the issue of whether circulating TF activity has an impact on cardiovascular mortality in patients with ACS. The associations between TF antigen and cardiovascular risk have been extensively studied with conflicting results. While some studies involving ACS patients reported no association between plasma TF levels and outcomes $[18,19]$, others found TF antigen to be an independent predictor of cardiovascular events $[12,14,16,17]$. However TF antigen levels may not adequately reflect the thrombogenic potential of circulating TF, [20,21]. Although we found a significant correlation between TF antigen and TF activity (data not shown), the indicative role of TF activity showed differences among subpopulations. In patients with AMI, plasma TF activity was significantly increased in those that died com- pared to those that survived, while in patients with uAP no such association was observed.

Sources of plasma TF include MP-associated TF, truncated degradation products of $\mathrm{TF}$, and the recently identified alternatively spliced TF variant that lacks a transmembrane-domain [4]. Herein we demonstrate that plasma membrane-bound TF was procoagulant, whereas soluble TF was inactive and that circulating MPs constitute the main reservoir of plasma TF activity. MPs have been shown to emerge from atherosclerotic plaques, leukocytes, platelets [22] and smooth muscle cells [23]. In AMI TF activity was associated with markers of myocardial necrosis. Since cardiomyocytes constitutively express TF and release TF positive procoagulant MP under inflammatory conditions, it is reasonable to speculate that MPs bearing TF in ongoing AMI may arise from necrotic myocardium [24,25]. MPs not only represent reliable hallmarks of cell damage, but also influence endothelial dysfunction, inflammation, and leukocyte adhesion $[26,27]$. Consistent with previous studies TF activity in the control group was below the assay's detection limit of 0.1 pM. [28]. The increase in TF activity observed in the present study, might reflect a systemic hypercoagulable state $[29,30]$. There is growing evidence that circulating TF is potentially active in an encrypted state, where it can bind FVII, but lacks proteolytic activity [31]. During thrombosis, encrypted TF can become available [1]. Among the mechanisms that control encryption and

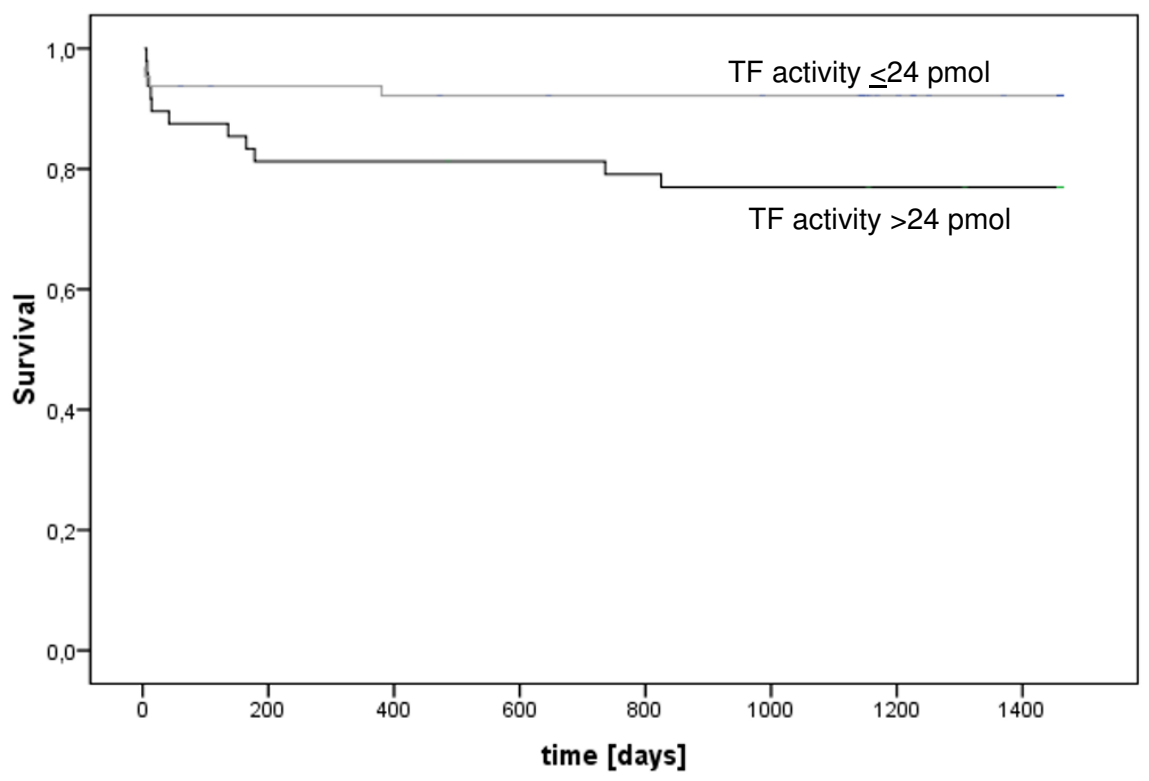

Figure I

Kaplan-Meier cardiovascular mortality curves according to low and high TF activity in AMI. Patients with AMI were divided in a group with high $(>24 \mathrm{pmol} / \mathrm{L})$ and a group with low plasma TF activities on admission $(\leq 24 \mathrm{pmol} / \mathrm{L}) .(\mathrm{p}=$ $0,03)$. 
Table 4: Coagulation markers in patients with stable Angina pectoris and an additional population of patients with ACS

\begin{tabular}{llll}
\hline & sAP $(n=28)$ & ACS $(n=36)$ & P \\
\hline TF activity (pmol) & $0.0 \pm 0.0$ & $0.5 \pm 0.16$ & 0.008 \\
TF activity + anti-TFPI Ab (pmol) & $0.98 \pm 0.4$ & $12.63 \pm 1.82$ & $<0.001$ \\
MP TF activity (nM) & $0.24 \pm 0.04$ & $0.39 \pm 0.07$ & 0.03 \\
\hline
\end{tabular}

decryption phosphatidyl serine exposure, calcium influx, lipid raft dissociation, and Cys ${ }^{186}-\mathrm{Cys}^{209}$ disulfide formation appear to play a role [21,31-33]. The significance of the present findings is supported by the fact that TF activity was an independent predictor for cardiovascular mortality in AMI even after adjustment for possible confounders. In accordance recent studies demonstrate, that MP linked tissue factor activity is associated to fibrinolysis failure in ST segment elevation infarction and is significantly elevated in the occluded coronary artery of STEMI patients [34,35]. Although the clinical relevance of circulating TF activity is still a matter of debate, our data together with these publications underline the pathophysiological relevance of circulating $\mathrm{TF}$ in coronary atherothrombosis. However, it has to be stressed that the small sample size limits the study due to low incidence of deaths during the follow-up.

\section{Supernatant}

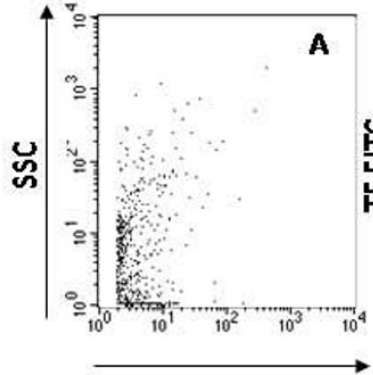

FSC

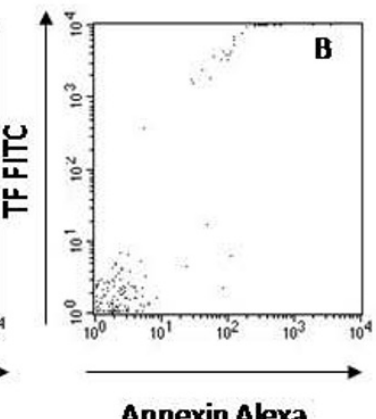

Annexin Alexa

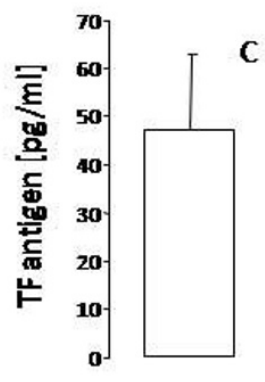

TF antigen

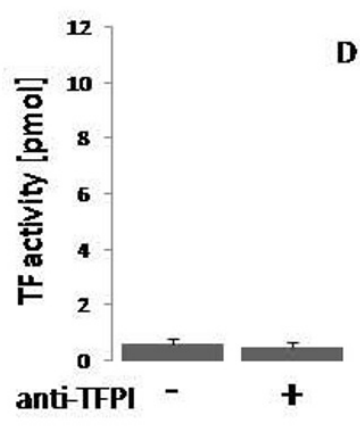

TF activity
D

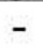

TFactivity MPassay

\section{Pellet}

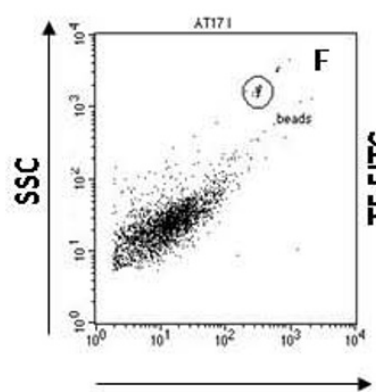

FSC

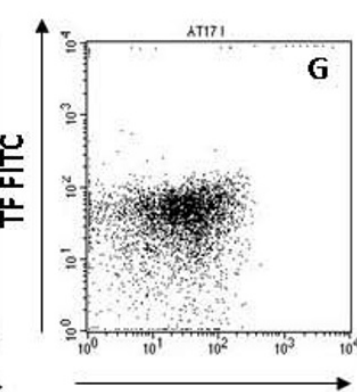

Annexin Alexa

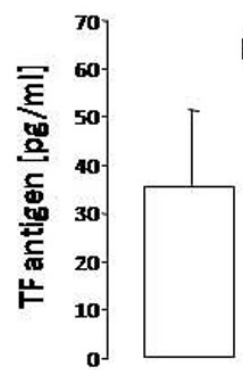

TF antigen

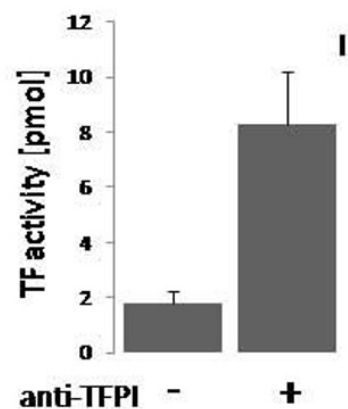

TFactivity

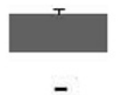

TF activity MP assay

Figure 2

Differential analysis of soluble TF (top row) and microparticle-associated TF (bottom row) in human plasma. In both supernatant and pellet fractions, the frequencies of TF+Annexin + microparticles were analyzed by FACS analysis. Representative dot blots of a patient with ACS are shown with (A, F) light-scatter-staining, and (B, G) specific-staining. (C, H) Concentrations of TF antigen were measured by immunoassay. (D, I) Plasma TF activity with or without (+/-) anti-TFPI-I was measured by FXa generation assay. (E, J) Specific microparticle-associated TF activity was measured following antibody capture of microparticles. Values are expressed as mean \pm SEM. 
Table 5: Number and cellular origin of circulating Microparticles in patients with ACS $(n=22)$

\begin{tabular}{ll}
\hline & ACS $(\mathrm{n}=22)$ \\
\hline Annexin+ Microparticles, $\left(10^{3} / \mu \mathrm{l}\right)$ & $9.7 \pm 3.85$ \\
\%TF positive & $56.8 \pm 5.01$ \\
\%CD4I positive & $13.4 \pm 2.19$ \\
\%CD66 positive & $15.0 \pm 3.22$ \\
\%CD66/CD4I double positive & $49.2 \pm 6.4$ \\
Annexin+ TF+ Microparticles, $\left(10^{3} / \mu \mathrm{l}\right)$ & $5.2 \pm 2.26$ \\
\%CD4I positive & $10.6 \pm 1.65$ \\
$\%$ CD66 positive & $9.8 \pm 3.22$ \\
\%CD66/CD4I double positive & $64.5 \pm 5.00$ \\
\hline
\end{tabular}

Our data corroborate the hypothesis that circulating TF presents a high risk blood condition that is prone to thrombosis. Therefore the plasma TF activity may serve as a marker for dysregulated coagulation to predict atherothrombotic risk. Furthermore, pharmacological control of plasma TF activity might reduce atherothrombotic risk.

\section{Competing interests}

The authors declare that they have no competing interests.

\section{Authors' contributions}

BAS participated in the design and coordination of the study, collected and assembled the data, carried out the flow cytometric and microparticle analyses and drafted the manuscript. SLB carried out biochemical analyses. AS, GD and PG collected and assembled the data. AS, NvB and AK participated in the study design, the discussion of study data and the revision of the manuscript. IO conceived the study, performed the statistical analysis and revised the manuscript. All authors read and approved the final manuscript

\section{Acknowledgements}

We thank Mrs B. Campbell, A. Stobbe and C. Bauer for invaluable technical assistance and R. Busch and T. Schuster for help with the statistical analysis. The study was supported by grants from the Deutsche Herzstiftung and the Wilhelm Sander-Stiftung.

\section{References}

I. Giesen PL, Rauch U, Bohrmann B, Kling D, Roque M, Fallon JT, Badimon JJ, Himber J, Riederer MA, Nemerson Y: Blood-borne tissue factor: another view of thrombosis. Proc Natl Acad Sci USA 1999, 96:23II-5.

2. Falati S, Liu Q, Gross P, Merrill-Skoloff G, Chou J, Vandendries E, Celi $A$, Croce $K$, Furie $B C$, Furie $B$ : Accumulation of tissue factor into developing thrombi in vivo is dependent upon microparticle $\mathbf{P}$-selectin glycoprotein ligand $\mathbf{I}$ and platelet $\mathbf{P}$-selectin. J Exp Med 2003, 197: 1585-98.

3. Chou J, Mackman N, Merrill-Skoloff G, Pedersen B, Furie BC, Furie B. Hematopoietic cell-derived microparticle tissue factor contributes to fibrin formation during thrombus propagation. Blood 2004, 104:3190-7.

4. Ramacciotti E, Hawley AE, Farris DM, Ballard NE, Wrobleski SK, Myers DD, Henke PK, Wakefield TW: Leukocyte- and plateletderived microparticles correlate with thrombus weight and tissue factor activity in an experimental mouse model of venous thrombosis. Thromb Haemost 2009, 101:748-54.
5. Wang JG, Manly D, Kirchhofer D, Pawlinski R, Mackman N: Levels of microparticle tissue factor activity correlate with coagulation activation in endotoxemic mice. J Thromb Haemost. 2009, 7(7): 1092-1098.

6. Szotowski B, Antoniak S, Rauch U: Alternatively spliced tissue factor: a previously unknown piece in the puzzle of hemostasis. Trends Cardiovasc Med 2006, 16: 177-82.

7. Falati S, Gross P, Merrill-Skoloff G, Furie BC, Furie B: Real-time in vivo imaging of platelets, tissue factor and fibrin during arterial thrombus formation in the mouse. Nat Med 2002, 8: II $175-81$.

8. Misumi K, Ogawa $H$, Yasue $H$, Soejima $H$, Suefuji $H$, Nishijama $K$, Takazoe K, Kugiyama K, Tsuji I, Kumeda K, Nakamura S: Comparison of plasma tissue factor levels in unstable and stable angina pectoris. Am J Cardiol I998, 8 I:22-6.

9. Suefuji H, Ogawa H, Yasue H, Kaikita K, Soejima H, Motojama T, Mizuno Y, Oshima S, Saito T, Tsuji I, Kumeda K, Kamikubo Y, Nakamura S: Increased plasma tissue factor levels in acute myocardial infarction. Am Heart J 1997, 134:253-9.

10. Falciani M, Gori AM, Fedi S, Chiarugi L, Simonetti I, Dabizzi RP, Prisco D, Pepe G, Abbate R, Gensini GF, Neri Serneri GG: Elevated tissue factor and tissue factor pathway inhibitor circulating levels in ischaemic heart disease patient. Thromb Haemost 1998, 79:495-9.

II. Mallat Z, Benamer H, Hugel B, Benessiano J, Steg PG, Freyssinet JM, Tedgui A: Elevated levels of shed membrane microparticles with procoagulant potential in the peripheral circulating blood of patients with acute coraonary syndromes. Circulation 2000, 101:84I-3.

12. Soejima H, Ogawa H, Yasue H, Kaikita K, Nishiyama K, Misumi K, Takazoe K, Miyao Y, Yoshimura M, Kugiyama K, Nakamura S, Tsuji I, Kumeda K: Heightened tissue factor associated with tissue factor pathway inhibitor and prognosis in patients with unstable angina. Circulation 1999, 99:2908-13.

13. Morange PE, Bickel C, Nicaud V, Schnabel R, Rupprecht HJ, Peetz D, Lackner KJ, Cambien F, Blankenberg S, Tiret L: Haemostatic factors and the risk of cardiovascular death in patients with coronary artery disease: the AtheroGene study. Arterioscler Thromb Vasc Biol 2006, 26:2793-9.

14. Morange PE, Blankenberg S, Alessi MC, Bickel C, Rupprecht HJ, Schnabel R, Lubos E, Münzel T, Peetz D, Nicaud V, Juhan-Vague I, Tiret $\mathrm{L}$ : Prognostic value of plasma tissue factor and tissue factor pathway inhibitor for cardiovascular death in patients with coronary artery disease: the AtheroGene study. J Thromb Haemost 2007, 5:475-82.

15. Morange PE, Simon C, Alessi MC, Luc G, Arveiler D, Ferrieres J, Amouyel P, Evans A, Ducimetiere P, Juhan-Vague I: Endothelial cell markers and the risk of coronary heart disease: the Prospective Epidemiological Study of Myocardial Infarction (PRIME) study. Circulation 2004, 109:1343-8.

16. Campo G, Valgimigli M, Ferraresi P, Malagutti P, Baroni M, Arcozzi C, Gemmati D, Percoco G, Parrinello G, Ferrari R, Bernardi F: Tissue factor and coagulation factor VII levels during acute myocardial infarction: association with genotype and adverse events. Arterioscler Thromb Vasc Biol 2006, 26:2800-6.

17. Seljeflot I, Hurlen M, Hole T, Arnesen $\mathrm{H}$ : Soluble tissue factor as predictor of future events in patients with acute myocardial infarction. Thromb Res 2003, I I I (6):369-72.

18. Roldan V, Marin F, Fernandez P, Lujan J, Martinez JG, Pineda J, Marco $P$, Sogorb F: Tissue factor/tissue factor pathway inhibitor system and long-term prognosis after acute myocardial infarction. Int I Cardiol 200 I, 78: I I5-9.

19. Malarstig A, Tenno T, Johnston N, Lagerqvist B, Axelsson T, Syvänen $A C$, Wallentin L, Siegbahn A: Genetic variations in the tissue factor gene are associated with clinical outcome in acute coronary syndrome and expression levels in human monocytes. Arterioscler Thromb Vasc Biol 2005, 25:2667-72.

20. Butenas S, Bouchard BA, Brummel-Ziedins KE, Parhami-Seren B, Mann KG: Tissue factor activity in whole blood. Blood 2005, 105:2764-70.

2I. Ahamed J, Versteeg HH, Kerver M, Chen VM, Mueller BM, Hogg PJ, Ruf W: Disulfid isomerization switches tisue factor from coagulation to cell signaling. PNAS 2006, 103:13932-37.

22. Leroyer AS, Isobe H, Leseche G, Castier Y, Wassef M, Mallat Z, Binder BR, Tedgui A, Boulanger CM: Cellular origins and throm- 
bogenic activity of microparticles isolated from human atherosclerotic plaques. J Am Coll Cardiol 2007, 49:772-7.

23. Tedgui $A$, Mallat $Z$ : Smooth muscle cells: another source of tissue factor-containing microparticles in atherothrombosis? Circ Res 2000, 87:8I-2.

24. Mumford AD, McVey JH: Tissue factor in the myocardium: evidence of roles in haemostasis and inflammation. Dis Markers 2004, 20:353-8.

25. Antoniak S, Boltzen U, Eisenreich A, Stellbaum C, Poller W, Schultheiss HP, Rauch U: Regulation of cardiomyocyte full-length tissue factor expression and microparticle release under inflammatory conditions in vitro. J Thromb Haemost 2009, 7:87I-8.

26. Morel O, Toti F, Hugel B, Bakouboula B, Camoin-Jau L, DignatGeorge F, Freyssinet JM: Procoagulant microparticles: disrupting the vascular homeostasis equation? Arterioscler Thromb Vasc Biol 2006, 26:2594-604.

27. Boulanger CM, Scoazec A, Ebrahimian T, Henry P, Mathieu E, Tedgui A, Mallat Z: Circulating microparticles from patients with myocardial infarction cause endothelial dysfunction. Circulation 200I, 104:2649-52.

28. Santucci RA, Erlich J, Labriola J, Wilson M, Kao KJ, Kickler TS, Spillert C, Mackman N: Measurement of tissue factor activity in whole blood. Thromb Haemost 2000, 83:445-54.

29. Putten RF van der, te Velthuis H, Aarden LA, ten Cate H, Glatz JF, Hermens WT: High-affinity antibodies in a new immunoassay for plasma tissue factor: reduction in apparent intra-individual variation. Clin Chem Lab Med 2005, 43:1386-9I.

30. Putten RF van der, te Velthuis HT, de Zwaan C, Aarden LA, Glatz JF, Hermens WT: State and diagnostic value of plasma tissue factor in early-hospitalised patients with chest pain. $\mathrm{Br} J$ Haematol 2005, I 31:91-9.

31. Bach RR: Tissue factor encryption. Arterioscler Thromb Vasc Biol 2006, 26:456-6I.

32. Jesty J, Beltrami E: Positive feedbacks of coagulation: their role in threshold regulation. Arterioscler Thromb Vasc Biol 2005, 25:2463-9.

33. Jesty J, Rodriguez J, Beltrami E: Demonstration of a threshold response in a proteolytic feedback system: control of the autoactivation of factor XII. Pathophysiol Haemost Thromb 2005, 34:7I-9.

34. Huisse MG, Ajzenberg N, Feldman L, Guillin MC, Steg PG: Microparticle-linked tissue factor activity and increased thrombin activity play a potential role in fibrinolysis failure in ST-segment elevation myocardial infarction. Thromb Haemost 2009, 101:734-40

35. Morel O, Pereira B, Averous G, Faure A, Jesel L, Germain P, Grunebaum L, Ohlmann P, Freyssinet JM, Bareiss P, Toti F: Increased levels of procoagulant tissue factor-bearing microparticles within the occluded coronary artery of patients with ST-segment elevation myocardial infarction: Role of endothelial damage and leukocyte activation. Atherosclerosis 2009, 204:636-4I.
Publish with Biomed Central and every scientist can read your work free of charge

"BioMed Central will be the most significant development for disseminating the results of biomedical research in our lifetime. "

Sir Paul Nurse, Cancer Research UK

Your research papers will be:

- available free of charge to the entire biomedical community

- peer reviewed and published immediately upon acceptance

- cited in PubMed and archived on PubMed Central

- yours - you keep the copyright
BioMedcentral 